\title{
Modifikasi Pati Beras Ketan Putih (Oryza Sativa I. Var. Glutinosa) Secara Pregelatinasi dengan Perbandingan Pati dan Air $(1: 1,25)$
}

\author{
Barmi Hartesi $^{*, 1}$, Ikhwansyah ${ }^{1}$, Amelia Soyata ${ }^{1}$ \\ Program Studi Farmasi, Sekolah Tinggi Ilmu Kesehatan Harapan Ibu Jambi \\ *E-mail:barmi.hartesi@gmail.com \\ (Submit 22/10/2021, Revisi 08/11/2021, Diterima 26/11/2021, Terbit 10/12/2021)
}

\begin{abstract}
Abstrak
Bahan tambahan (eksipien) yang ada di Indonesia umumnya masih banyak yang diimpor dari negara lain untuk memenuhi kebutuhan industri farmasi, diantaranya adalah pati yang merupakan eksipien utama dalam sediaan tablet, dimana pati sebanyak $5-75 \% \mathrm{w} / \mathrm{w}$ bisa digunakan sebagai bahan pengisi dalam pembuatan tablet, Oleh karena itu perlu dilakukan modifikasi secara pregelatinasi agar bisa digunakan sebagai bahan pengis. Tujuan penelitian ini untuk mendapatkan karakterisitik dari pati beras ketan putih yang dimodifikasi dengan pregelatinasi dengan perbandingan pati dan air $(1: 1,25)$. Penelitian ini dilakukan dengan metode experimental di laboratorium dengan cara mengisolasi pati beras ketan putih dan selanjutnya dibuat pati pregelatinasi sebanyak 9 formula dengan perbandingan pati dan air $(1: 1,25)$ serta variasi suhu $(45,55$ dan $650 \mathrm{C})$ dan rpm $(200,250$ dan 300), pati pregelatinasi yang sudah terbentuk dilakukan evaluasi (rendemen, organoleptis, $\mathrm{pH}$, susut pengeringan, distribusi partikel, laju alir dan sudut istirahat, bobot jenis nyata dan mampat, faktor hausner,kompresibilitas, SEM, XRD). Hasil standariasi pati alami Beras Ketan Putih didapatkan hasil yang baik terkecuali pada cemaran logam berat merkuri $(\mathrm{Hg})$, pada uji kapang khamir dan pH.Pada pati pregelatinasi mendapatkan hasil karakteristik yang baik setiap formulanya. Pati alami yang awalnya tidak mengalir setelah dibuat pregelatinasi semua formula dapat mengalir dan memperbaiki sudut istirhat serta nilai kompresibilitasnya yang baik.Pati pregelatinasi didapatkan hasil yang baik pada semua formula dan dengan meningkatanya suhu dan rpm akan memperbaiki karaktersistiknya. F9 adalah formula yang terbaik dengan menggunakan suhu $650 \mathrm{C}$ dan $300 \mathrm{rpm}$.
\end{abstract}

Kata kunci: Beras Ketan Putih, Pati, Pregelatinasi, Rpm dan Suhu

\section{Pendahuluan}

Bahan tambahan (eksipien) yang ada di Indonesia umumnya masih banyak yang diimpor dari negara lain untuk memenuhi kebutuhan industri farmasi, diantaranya adalah pati yang merupakan eksipien utama dalam sediaan tablet(1).Pati berasal dari tanaman yang mengandung karbohidrat tinggi, salah satunya adalah beras ketan. Beras ketan memiliki kandungan pati yang tinggi, 
dengan kadar amilosa 1-2\% dengan kadar amilopektin 98-99\%, semakin tinggi kandungan amilopektinnya semakin lekat sifat beras tersebut. Kadar amilopektin yang tinggi menyebabkan pati beras ketan putih sangat mudah mengalami gelatinisasi bila ditambahkan dengan air dan memperoleh perlakuan pemanasan dibwah suhu gelatinasi yaitu $70{ }^{\circ} \mathrm{C}(2)$. Pati alami tidak bisa digunakan sebagai bahan pengisi pada pembuatan tablet kempa langsung karena sifat alir dan kompresibilitas yang buruk, pati alami dapat dimodifikasi sehingga menyebabkan perubahan fisiknya atau perubahan karakterisasi kimiawinya. Salah satu cara modifikasi pati secara fisika yaitu dengan cara pregelatin, di mana pati yang diolah secara alami lalu diberikan perlakuan tambahan melalui penambahan air dengan jumlah tepat dan pemanasan pada suhu sesuai dibawah suhu gelatinasi.Pati modifikasi secara pregelatin memiliki keunggulan daripada pati alami yaitu mampu meningkatkan sifat alir karena pati pregelatin yang terbentuk dari proses penyatuan partikel-partikel serbuk menghasilkan granul(3). Salah satu modifikasi pati secara fisika yaitu dengan cara pregelatinasi, metode ini dapat mengubah struktur granul pati serta dapat mengembang di dalam air dan memiliki ukuran partikel yang lebih besar yaitu granul sehingga akan memperbaiki sifat alir dan kompresibilitas dari pati tersebut(4).

\section{Metode}

\section{Alat}

Alat yang digunakan untuk penelitian ini berupa Scanning Electron Microscopy (SEM) (Hitachi S3400N), XRD (X-Ray Diffraction ) (XPERT PRO PANanalytical pw 30/40), Forced-Air Drying Oven(ZRD5110), Moisture balance (KERN), Homogenizer(IKA RW 20 Digital), Hot Plate (Thermo Scentific), timbangan analitik (Shimadzu), Granule Sieve, Tap Density Tester (TDT-1-H), Microskop(Olympus21),Flow Tester, Blender, Lumpang dan Alu, alat-alat gelas (Pyrex), pH Meter HANNA, Botol Timbang, Kurs porselin, kertas

\section{Bahan}

Bahan yang digunakan pada penelitian yaitu Beras ketan putih yang diambil dari Kabupaten Kerinci Kecamatan Air Hangat Timur, Aquadest

\section{Prosedur Rinci}

Metode yang digunakan adalah metode ekperimental berupa penelitian di Laboratorium. Tahapan kerja yang akan dilakukan meliputi pengambilan bahan di Kabupaten Kerinci Kecamatan Air Hangat Timur, determinasi tanaman beras ketan putih, isolasi pati beras ketan putih alami, pemeriksaan karakteristik pati alami, pembuatan modifikasi pati secara pregelatinasi, evaluasi pati alami dan pregelatinasi.

1. Formula Pati Pregelatinasi dengan variasi suhu dan pengadukan

Formula pati pregelatinasi dibuat sebanyak 9 formula dengan variasi suhu dan pengadukan yang berbeda dapat dilihat pada tabel 1 . 
2. Melakukan isolasi dan evaluasi pati beras ketan putih alami

Isolasi Pati beras ketan putih

Beras ketan ditimbang sebanyak $60 \mathrm{~kg}$ lalu dicuci hingga bersih. Beras ketan kemudian direndam menggunakan aquadest selama 18 jam lalu diblender kemudian disaring menggunakan kain flanel, kemudian di endapkan selama 3 jam lalu di oven pada suhu 50 oC selama 8 jam setelah itu digerus kemudian diayak menggunakan mesh no 60 .

3. Karakterisasi pati beras ketan alami

a. Rendemen

Rendemen pati yang diperolehdapat dihitung dengan Rumus

$$
\text { : Rendemen }(\%)=\frac{\text { Berat endapan (gram) }}{\text { Berat simplisia besah (gram) }} \times 100 \%(5)
$$

b. Organoleptis

Mengamati oraganoleptis pati yang meliputi bentuk, warna, bau dan rasa(6)

c. Uji Kadar Air

Pati ditimbang sebanyak 10 gram dan dimasukkan ke dalam krus lalu dioven selama 3 jam pada suhu 105 oC(7)

d. Mikroskopik

Ditimbang pati sebanyak $100 \mathrm{mg}$ dan diletakkan pada gelas objek.

Selanjutnya ditambahkan 2 tetes aquadest, lalu diamati susunan pati, bentuk hilus dan lamela dari pati di bawah mikroskop dengan perbesaran 400x (3)

e. Uji kadar Abu

Cawan porselin dibebas lemakkan, sampel kering sebanyak 3 gram

dipanaskan dalam cawan porselin sampai warna hitam. Kemudian cawan porselin ditempatkan dalam tanur dengan suhu 550 oC dan sampai diperoleh abu tidak berwarna(8)

f. Cemaran Logam Berat

Penentuan kandungan cemaran logam berat dilakukan menggunakan instrument Atomic absorption spektrophotometry (AAS). Dalam persyaratan $\mathrm{SNI}$ kadar maksimal logam-logam berat adalah sebagai berikut, Timbal $(\mathrm{Pb})$ $1,0 \mathrm{mg} / \mathrm{kg}$, tembaga (Cu) $10,0 \mathrm{mg} / \mathrm{kg}$, Seng (Zn) 40,0 mg/kg, Raksa $(\mathrm{Hg}) 0,05$ $\mathrm{mg} / \mathrm{kg}$, Arsen (As) $0,5 \mathrm{mg} / \mathrm{kg}(9)$ Pengujia ini dilakukan dengan mengirimkan sampel ke Laboratorium Pusat Survei Geologi Bandung

g. Cemaran Mikroba

Uji cemaran mikroba yang dilakukan diantaranya :

a) Angka Lempeng Total

b) APM Escheria coli

c) Basilus cereus

d) Kapang(10) Pengujian ini dilakukan dengan mengirimkan sampel ke Labkesda DKI Jakarta

\section{Pembuatan Pati Beras Ketan Pregelatinasi}

Pati beras ketan yang baik terbentuk dengan perbandingan air, pati dan penggunaan suhu serta pengadukan yang tepat dan benar, pati pregelatinasi dibuat sebanyak sembilan formula dengan perbandingan rasio pati dan air 1:1,25 dan suhu pemanasan 45, 55, 65 oC serta pengadukan masing-masing 200, 250 dan $300 \mathrm{rpm}$. 
Formula I (F1) dibuat dengan cara mencampurkan pati dan air dengan perbandingan 1:1,25 air dipanaskan sampai suhu 45 oC pada water bath, suhu 45 oC dijaga selama 10 menit dengan pengadukan $200 \mathrm{rpm}$ menggunakan homogenizer hingga masa terbentuk masa kental. Massa kental tersebut dikeringkan pada suhu 45 oC selama 48 jam. Setelah kering, pati lalu diayak dengan mesh 20 , untuk formula 2 sampai formula 9 (F2-F9) dilakukan dengan cara yang sama namun berbeda suhu dan rpm.

a. Pemeriksaan Sifat Fisika kimia pati alami dan pregelatinasi

1. Rendemen pati Rendemen $(\%)=\frac{\text { Berst endapan (gram) }}{\text { Berat simplsas bash (gram) }} \times 100 \%(5)$

2. Organoleptis

Mengamati organoleptis pati yang meliputi bentuk, warna, bau dan rasa(6)

3. Uji pH

Pati ditimbang sebanyak 1 gram dan didispersikan dalam $10 \mathrm{ml}$ aquadest, ditentukan $\mathrm{pH}$ nya menggunakan $\mathrm{pH}$ meter(11)

4. Susut Pengeringan

1 gram pati dimasukkan ke dalam alat moisture balance. Alat moisture balance diatur pada suhu $105 \mathrm{oC}$ dan waktu otomatis, kemudian ditunggu hingga bobot konstan lalu ditimbang(7)

5. Distribusi Partikel

Sebanyak 100 gram masing-masing sampel pati dimasukkan ke dalam pengayak dengan nomor 10, 40, 44 dan 60 mesh yang telah disusun

berurutan mulai dari bawah ke atas, dan dipasang pada mesin penggerak (vibrator). Pengayak di atur pada kecepatan $30 \mathrm{rpm}$ selama 20 menit. Serbuk yang tertinggal pada masing-masing ayakan ditimbang dan dihitung masingmasing persentase beratnya( 1 )

6. Laju Alir dan Sudut Istirahat

Sebanyak 25 gram pati ditimbang.Kemudian pati tersebut dituang melalui tepi corong secara perlahan-lahan ke dalam corong yang bagian bawahnya $t$ ertutup.Tutup corong bagian bawah dibuka secara perlahan-lahan dan pati dibiarkan mengalir keluar. Dicatat waktu yang diperlukan (detik) sampai pati melewati corong dengan menggunakan stopwatch(1)

Sebanyak 25 gram pati ditimbang.Pati tersebut kemudian dituang melalui tepi corong secara perlahan-lahan ke dalam corong yang bagian bawahnya tertutup.Tutup corong bagian bawah dibuka secara perlahan-lahan dan pati dibiarkan mengalir keluar hingga membentuk kerucut. Diukur tinggi pati yang berbentuk kerucut tersebut dan jari-jarinya(1)

7. Bobot jenis nyata dan mampat

a. Bobot jenis nyata

Sebanyak 25 gram serbuk (Wo) dimasukkan kedalam gelas ukur 250 $\mathrm{ml}$ dicatat volumenya $(\mathrm{Vo})$ dan bobot jenis nyata ( $\rho$ nyata) dapat dihitung dengan persamaan:

$P$ nyata $=\frac{\mathrm{W}}{\mathrm{V} 0}(12)$ 
b. Bobot jenis mampat

Sebanyak 25 gram serbuk (W) dimasukkan kedalam gelas ukur $100 \mathrm{ml}$, kemudian diberikan ketukan sebanyak 1250 kali, dicatat volumenya (Vt1), kemudian diulangi ketukan sebanyak 1250 kali, dicatat volumenya (Vt2). Jika Vt1 dan Vt2 tidak lebih dari $2 \mathrm{ml}$, maka dipakai Vt1. Bobot jenis mampat (mampat) dapat dihitung dengan persamaan : $\rho$ mampat $=\frac{\mathrm{w}}{\mathrm{V} \mathrm{r} 1}$

c. Faktor Hausner

Dihitung dengan rumus: $\mathrm{FH}=\frac{\text { plampse }}{\text { p. Pyata }}(6)$

9. Kompresibilitas $(\mathrm{Kp})$ zat uji dihitung dengan persamaan:

$\mathrm{Kp}=\frac{\text { B] Mampat-8] aysata }}{\text { Bfmampar }} \times 100 \%(6)$

10. Analisis Instrumen

a. SEM (Scanning Elektron Microscopy)

Scanning Electron Microscope (SEM) adalah sebuah mikroskop elektron yang didesain untuk mengamati permukaan objek solid secara langsung.SEM memiliki perbesaran $10-3.000 .000$ kali, depth of field $4-0.4 \mathrm{~mm}$ dan resolusi sebesar $1-10 \mathrm{~nm}$.

besar, komposisi digunakan Pengujian ini UNAND

Kombinasi dari perbesaran yang tinggi, depth of field yang resolusi yang baik, kemampuan untuk mengetahui dan informasi kristalografi membuat SEM banyak untuk keperluan penelitian dan industri(13) dilakukan di laboratorium teknik mesin

b. XRD (X-Ray Diffraction)

Difraksi sinar- $X$ merupakan suatu teknik yang digunakan menentukan sistem kristal (kubus, tetragonal, ortorombik, rombohedral, heksagonal, monoklin, triklin), kualitas kristal (kristal t unggal, polikristalin, dan amorf), simetri kristal, menentukan cacat kristal, mencari parameter kristal (parameter kisi, jarak antar atom, jumlah atom per unit sel), identifikasi campuran dan analisis kimia. Prinsip kerjanya yaitu ketika sinar$X$ yang monokromatik jatuh pada sebuah kristal maka sinar- $X$ tersebut akan dihamburkan ke segala arah, tetapi karena ada keteraturan letak atom-atom dalam kristal maka pada arah tertentu saja gelombang hambur akan berinterferensi konstruktif dan pada arah lainnya akan berinterferensi destruktif. Hasil analisis dengan XRD adalah berupa difraktogram yang berupa susunan garis atau puncak dengan intensitas dan posisi

berbeda- beda yang spesifik pada material yang dianalisis. Tiap fase kristalin mempunyai susunan difraktogram yang

karakteristik, maka dapat digunakan sebagai sidik jari untuk uji identifikasi (14) Pengujian ini dilakukan di laboratorium Fisika FMIPA UNP 


\section{Hasil}

Pengambilan dan Determinasi Tanaman beras ketan puth

Berdasarkan hasil determinasi Pati beras ketan putih yang diambil di Kabupaten Kerinci Kecamatan Air Hangat Timur menunjukkan bahwa beras ketan putih yang digunakan adalah Oryza Sativa var.glutinosa

\section{Hasil Pembuatan Pati Alami beras ketan putih}

Hasil pembuatan pati beras ketan putih alami yang didapatkan dari $59 \mathrm{~kg}$ beras ketan putih didapatkan pati alami sebanyak 2,488 $\mathrm{kg}$ dengan nilai rendemen 4,21\%

\section{Hasil Standarisasi Pati Beras ketan}

Pengujan standarisasi pati beras ketan putih alami dilakukan agar didapatkan pati yang berstandar Pharmaceutical grade.Pengujian ini mendapatkan hasil yang hampir memenuhi standar kecuali pada uji pH, Angka Kapang Khamir dan $\mathrm{Hg}$ (merkuri). Hasil standarisasi dapat dilihat pada tabel 2.

Hasil Evaluasi Pati alami dan pregelatinasi

\section{Laju Alir}

Hasil Laju alir dapat diihat pada gambar 1 .

\section{Kompresibilitas}

Hasil uji kompresibilitas dapat dilihat pada gambar 2

\section{Uji Instrumen}

Hasil uji instrumen dapat dilihat pada gambar 3 dan 4.

\section{Pembahasan}

Hasil determinasi yang dilakukan di Laboratorium Fakultas Teknologi Industri Pertanian Universitas Padjadjaran beras ketan putih yang digunakan dalam penelitian ini merupakan beras ketan putih jenis Oryza sativa $L$ var. glutinosa yang didapatkan di daerah Kabupaten Kerinci. Tujuan dilakukan determinasi untuk melihat spesifikasi dari tanaman yang diteliti.. Setelah dilakukan pembuatan patiselanjutnya dilakukan uji organoleptis pati alami dan pati pregelatinasi dengan mengamati bau, rasa, bentuk dan warna dari pati. Hasilnya adalah tidak berbau, tidak berasa, bentuk serbuk dan warna putih sesuai dengan persyaratan yang ada pada Handbook of pharmaceutical excipient(7).Hasil uji kadar air pati alami menunjukkan nilai yang sesuai dengan literatur yaitu $1,08 \%$ kurang dari $<14 \%$. 
.tujuan dilakukannya evaluasi kadar air untuk meningkatkan ketebalan lapisan yang mengadsorpsi air yang akan meningkatkan kekuatan jembatan cair yang terbentuk diantara partikel serbuk, meningkatnya kadar air akan menurunkan kemampuan serbuk untuk mengalir serta berpengaruh terhadap cemaran mikroba selama penyimpanan (11).Uji cemaran logam berat dilakukan agar mendapatkan bahan yang aman untuk digunakan. Berdasarkan dari hasil uji diketahui pati beras ketan putih mengandung $\mathrm{Hg}$ yang melewati batas maksimum yaitu $0,057 \mathrm{mg} / \mathrm{kg} . \mathrm{Kadar} \mathrm{Hg}$ yang berlebih dapat menyebabkan tremor jika terus berlanjut dapat menyebabkan pengurangan pendengaran, penglihatan, atau daya ingat(15). tersebarnya logam berat $\mathrm{Hg}$ di tanah, perairan, ataupun udara bisa melalui berbagai jalur, seperti pembuangan limbah industri secara langsung, baik limbah padat maupun limbah cair yang dibuang ke tanah, udara dan air. Sebagian senyawa $\mathrm{Hg}$ yang lepas ke lingkungan akan mengalami proses metilasi dan menjadi metil merkuri $(\mathrm{CH} 3 \mathrm{Hg})$ oleh mikroorganisme dalam air dan tanah(16). Setelah dilakukannya uji kadar cemaran mikroba pati alami didapatkan hasil yang baik pada uji ALT dan uji pada cemaran mikroba E-coli dimana berdasarkan persyaratan SNI kadar cemaran angka lempeng total yaitu maksimal $1.106 \mathrm{koloni} / \mathrm{gram}$, cemaran mikroba E-coli pati yaitu maksimal 10 APM/gram ) dan mikroba kapang pati ubi jalar yaitu maksimal 1 ×104 koloni/gram. Pada pengujian angka kapang khamir melebihi batas cemaran yaitu 7.4 x 104(17). Pada pengujian susut pengeringan pada pati alami dan pati pregelatinasi di dapatkan hasil yang sesuai dengan standart pati yang ada pada handbook of pharmaceutical yaitu $<15 \%$ (7). Sifat alir serbuk sangat penting untuk pembuatan tablet yang efisien. Aliran serbuk atau granul yang baik untuk dikempa sangat penting untuk memastikan pencampuran yang efisien untuk tablet kempa(11). Pada pengujian kali ini di dapatkan hasil yang baik yaitu pada formula 9 dimana serbuk yang mengalir yaitu sebanyak 9,02 g/detik yang mana menurut standar laju alir yang baik adalah $10 \mathrm{~g} /$ detik.sudut istirahat telah digunakan sebagai metode tidak langsung untuk mengukur mampu alir granul karena hubungannya dengan kohesi antarpartikel. Nilai yang baik untuk pengujian faktor hausner yaitu mendekati 1 hal ini akan berbanding lurus dengan sifat alir yang baik. Faktor hausner didapatkan dari hasil perhitungan perbandingan antara bobot jenis mampat dengan bobot jenis nyata. Kompresibilitas yang tinggi akan menyebabkan tablet memiliki waktu hancur yang lama. Pada pengujian kompresibiltas didapatkan hasil pada pati alami yaitu sebesar 42,24 dan pada pati pregelatinasi didapatkan hasil yang terbaik pada formula 8 dan 9 yaitu 6,24 ini menunjukkan pengaruh suhu dan rpm dimana semakin tinggi suhu dan rpm maka akan menghasilkan nilai kompresibilitas yang baik, menurut literatur nilai yang baik berada pada rentan 5-15\%(6). Evaluasi yang terakhir yaitu analisis instrumen (SEM dan XRD) pengujian SEM dilakukan untuk mengetahui morfologi permukaan dengan menggunakan perbesaran $750 x$ dan $1500 x$ dapat dilihat bahwa permukaan pati alami dan pregelatinasi berbentuk seperti limas segilima dan tidak terjadi perubahan bentuk hanya terjadi perubahan kerapatan hal ini menunjukkan pengaruh dari suhu dan rpm pada pembuatan pati pregelatinasi(7). Pengujian analisis XRD bertujuan untuk mengidentifikasi fasa kristalin dalam material. Dari hasil uji yang telah dilakukan pola difraksi yang terbentuk terlihat bahwa pati alami dan pati pregelatinasi memiliki pola difraksi yang tidak begitu tajam hal ini menunjukkan pati berbentuk semi kristalin sama dengan penelitian yang telah dilakukan sebelumnya(4). 
Bahwa pati pregelatinasi berbentuk semi kristalin. Suhu pemanasan dapat mempengaruhi derajat kristalinitas bahan, yang mana kenaikan suhu dapat mempengaruhi derajat kristalinitas dimana molekul senyawa kompleks tersusun semakin teratur dengan meningkatnya suhu(18).

\section{Kesimpulan}

Berdasarkan hasil penelitian yang telah dilakukan dapat disimpulkan bahwa modifikasi pati beras ketan putih secara pregelatinasi yang dihasilkan dapat memperbaiki karakteristik pati alami terlihat pada F9 dimana pati memiliki kompresibilitas dan sifat alir yang baik dimana semakin tinggi suhu dan semakin tinggi rpm pengadukan semakin baik pati yang dihasilkan.

\section{Daftar Pustaka}

1. Ardana M, Hariati, Rijai L. Karakterisasi Fisikokimia Pati Buah Pisang Talas (Musa Paradisiaca Var Sapientum L) Sebagai Eksipien Formulasi Tablet. Pros Semin Nas Kefarmasian. 2015;24-5.

2. Larasati D, Sumartini, Widianti T. Perbandingan tepung beras ketan putih (Ci asem) dengan tepung beras ketan hitam (Setail) dan konsentrasi buah murberi (Morus nigra L) terhadap karakteristik opak ketan hitam. Tugas akhir Dipublikasikan. 2016;

3. Sari KL., Prasetia A, ARISANTI S. Pengaruh Rasio Amilum: Air dan Suhu Pemanasan Terhadap Sifat Fisik Amilum Singkong Pregelatin yang ditunjukkan Sebagai Eksipien Tablet. Jp Farm. 2008;50-67.

4. Hartesi B, Sriwidodo, Abdassah M, Chaerunisaa AY. Starch as pharmaceutical excipient. Int J Pharm Sci Rev Res. 2016;41(2):59-64.

5. 5. Rendowaty A, Munarsih E, Fizmawati. Isolasi Pati dari Tepung Ubi Jalar Ungu. Bakti Farm. 2018;(2):1-6.

6. Suhery WN, Anggraini D, Endri N. Pembuatan Dan Evaluasi Pati Talas (Colocasia esculenta Schoot) Termodifikasi dengan Bakteri Asam Laktat (Lactobacillus sp). J Sains Farm Klin. 2015;1(2):207.

7. 7. Rowe CR, Sheskey JP, Owen CS. Hanbook of Pharmaceutical Excipients Sixth Edition. Sixth Edit. RPS Publishing; 2009.

8. 8. Suriani. Analisis Proksimat Pada Beras Ketan Varietas Putih (Oryza sativa glutinosa). AL- Kim. 2015; Vol 3:92-102.

9. BSN. Standar Nasional Indonesia. 1998.

10. BSN. Standar Nasional Indonesia. Badan Standarisasi Nasional; 2009.

11. Khairunnisa R, Nisa M, Riski R, Fatmawaty A, Tinggi S, Makassar IF, et al. Evaluasi Sifat Alir Dari Pati Talas Safira (Colocasia esculenta var Antiquorum) Sebagai Eksipien Dalam Formulasi Tablet. J Pharm Med Sci. 2016;1(1):22-6.

12. Octavia DM, Halim A, Indriyani R. Pengaruh Besar Ukuran Partikel Terhadap Sifat sifat Tablet Metronidazol. J Farm Higea. 2012;4(2):74-92.

13. Farikhin F, Ngafwan, Sedyono J. Analisa Scanning Electron Microscope Komposit Polyester dengan Filler Karbon Aktif dan Karbon Non Aktif. Publ IIm. 2016; 
14. Masruroh, Manggara A, Papilaka T, Triandi R. Penentuan ukuran Kristal (crystalilite size) lapisan tipis PZT dengan metode XRD melalui pendekatan persamaan Debye Scherrer. Erud (Journal Educ Innov. 2013;1 No 2:24-9.

15. Suyanto A, Kusmiyati S, Retnaningsih C. Residu Logam Berat Ikan Dari Perairan

Tercemar Di Pantai Utara Jawa Tengah (Residual Heavy Metals In Fish From

Contaminated Water In North Coast Of Central Java). J Pangan dan Gizi. 2010;01(02).

16. Ariansyah KA, Yuliati K, J SHR. Pengaruh Analisis Kandungan Logam Berat ( $\mathrm{Pb}$,

$\mathrm{Hg}$, Cu dan As ) Pada Kerupuk Kemplang Di Desa Tebing Gerinting Utara , Kecamatan Indralaya. Fistech. 2012;1:69-77.

17. Noviawati DAS, Bintari NWD, Sudiari M. Cemaran Angka Lempeng Total (Alt) Dan Angka Kapang Khamir (Akk) Pada Bolu Kukus Dengan Lama Penyimpanan 3 Hari. Bali Med J. 2018;5(2):257-64.

18. Budi FS, Hariyadi P, Budijanto S, Syah D. Kristalinitas dan Kekerasan Beras Analog yang Dihasilkan Dari Proses Ekstrusi Panas Tepung Jagung ( Crystallinity and Hardness of Rice Analogue Produced from Corn Flour through Hot Extrusion Processes ). 2017;28(1):46-54.

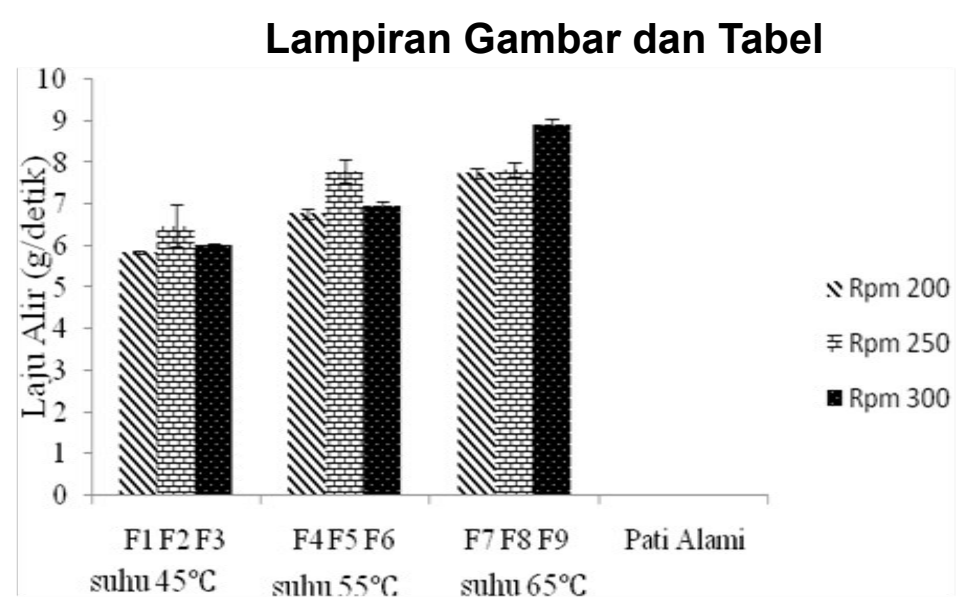

Gambar 1. Hasil Uji Laju Alir Pati Alami dan Pregelatinasi

pregelatinasi

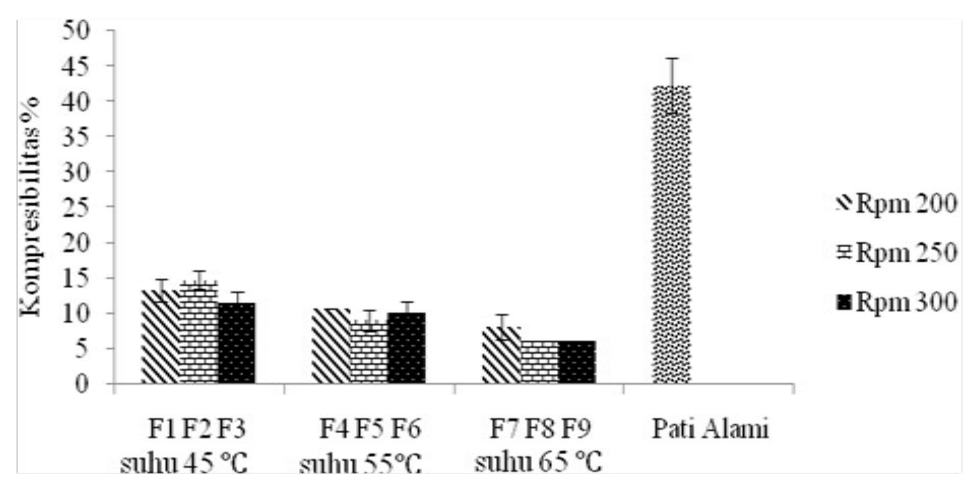


Gambar 2. Hasil Uji Kompresibilitas Pati Alami dan Pregelatinasi

Pregelatinasi

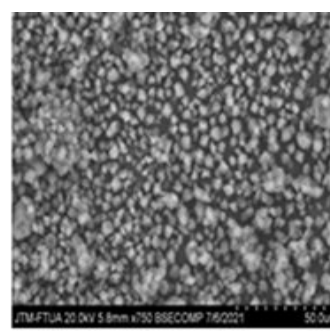

Pati Alami perbesaran750x
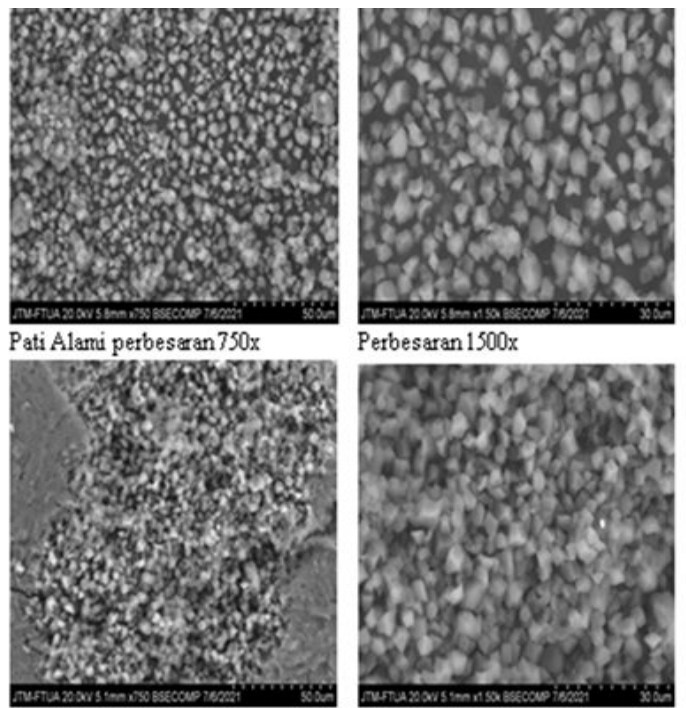

Perbesaran $1500 x$

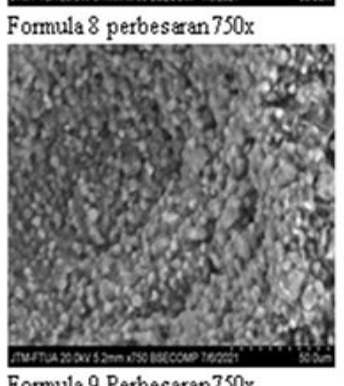

Formula 9 Perbesaran $750 x$

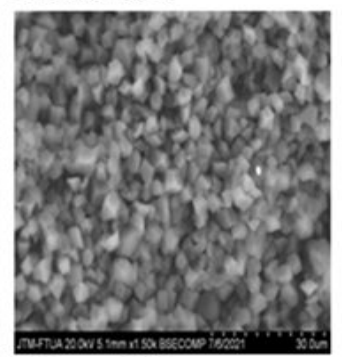

Perbesaran $1500 x$

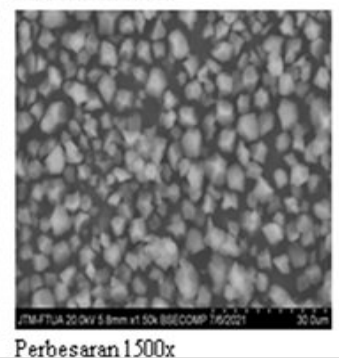

Gambar 3. Hasil Uji SEM Pati alami dan pregelatinasi dengan perbesaran 750 dan 1500

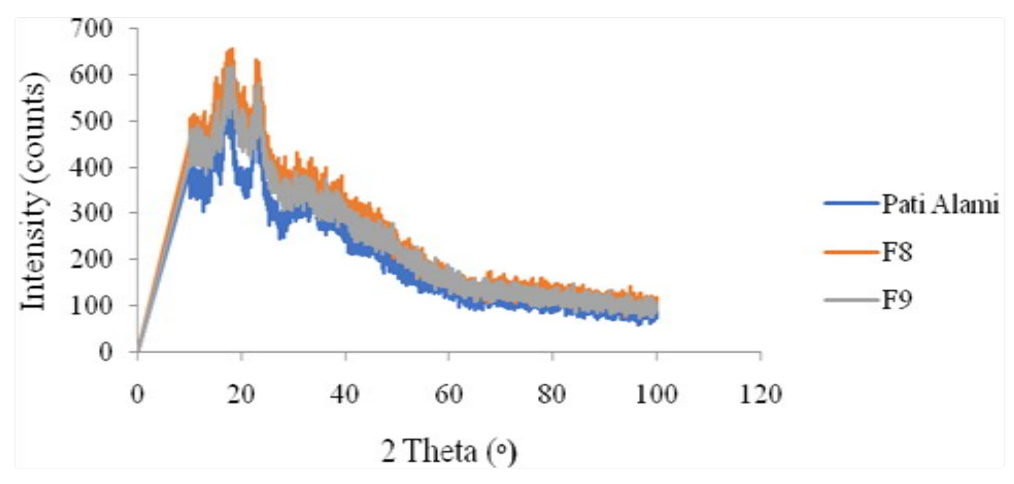

Gambar 4. Hasil Uji XRD Pati alami, formula 8 dan 9 
Tabel 1 Formula Pati Pregelatinasi dengan variasi suhu dan pengadukan

\begin{tabular}{cccc}
\hline Formula & Pati : Air & Suhu $\left({ }^{\circ} \mathrm{C}\right)$ & $\begin{array}{c}\text { Pengaduk } \\
\text { an (rpm) }\end{array}$ \\
\hline F1 & & 200 \\
F2 & 45 & 250 \\
F3 & & 300 \\
F4 & & 200 \\
F5 & $1: 1,25$ & 55 & 250 \\
F6 & & 300 \\
F7 & & 200 \\
F8 & & 250 \\
F9 & 65 & 300 \\
\hline
\end{tabular}

Tabel 2 Hasil Standarisasi Pati Alami

\begin{tabular}{|c|c|c|c|c|c|c|}
\hline \multicolumn{7}{|c|}{ Standarisasi Pati Alami } \\
\hline \multirow{2}{*}{ No } & Parameter & Pengujian & & Syarat & & \\
\hline & & & SNI & HOPE & F.I & Ket \\
\hline 1 & Rendemen & $4,21 \%$ & - & - & - & $\sqrt{ }$ \\
\hline \multirow[t]{6}{*}{2} & Organolepti & & & & & \\
\hline & $\mathrm{s}$ & & & & & \\
\hline & Warna & Putih & & Putih & Putih & $\sqrt{ }$ \\
\hline & Bentuk & Serbuk & & Serbuk & Serbuk & $\sqrt{ }$ \\
\hline & Bau & Tidak berbau & & Tidak berbau & Tidak berbau & $\sqrt{ }$ \\
\hline & Rasa & Tidak berasa & & Tidak berasa & Tidak berasa & $\sqrt{ }$ \\
\hline 3 & Kadar air & $1,08 \%$ & $<14 \%$ & - & - & $\sqrt{ }$ \\
\hline 4 & $\begin{array}{c}\text { Susut } \\
\text { pengeringan }\end{array}$ & $9,65 \%$ & $<15 \%$ & - & - & $\sqrt{ }$ \\
\hline 5 & $\mathrm{pH}$ & 4,1 & - & $4,5-7$ & - & $x$ \\
\hline
\end{tabular}




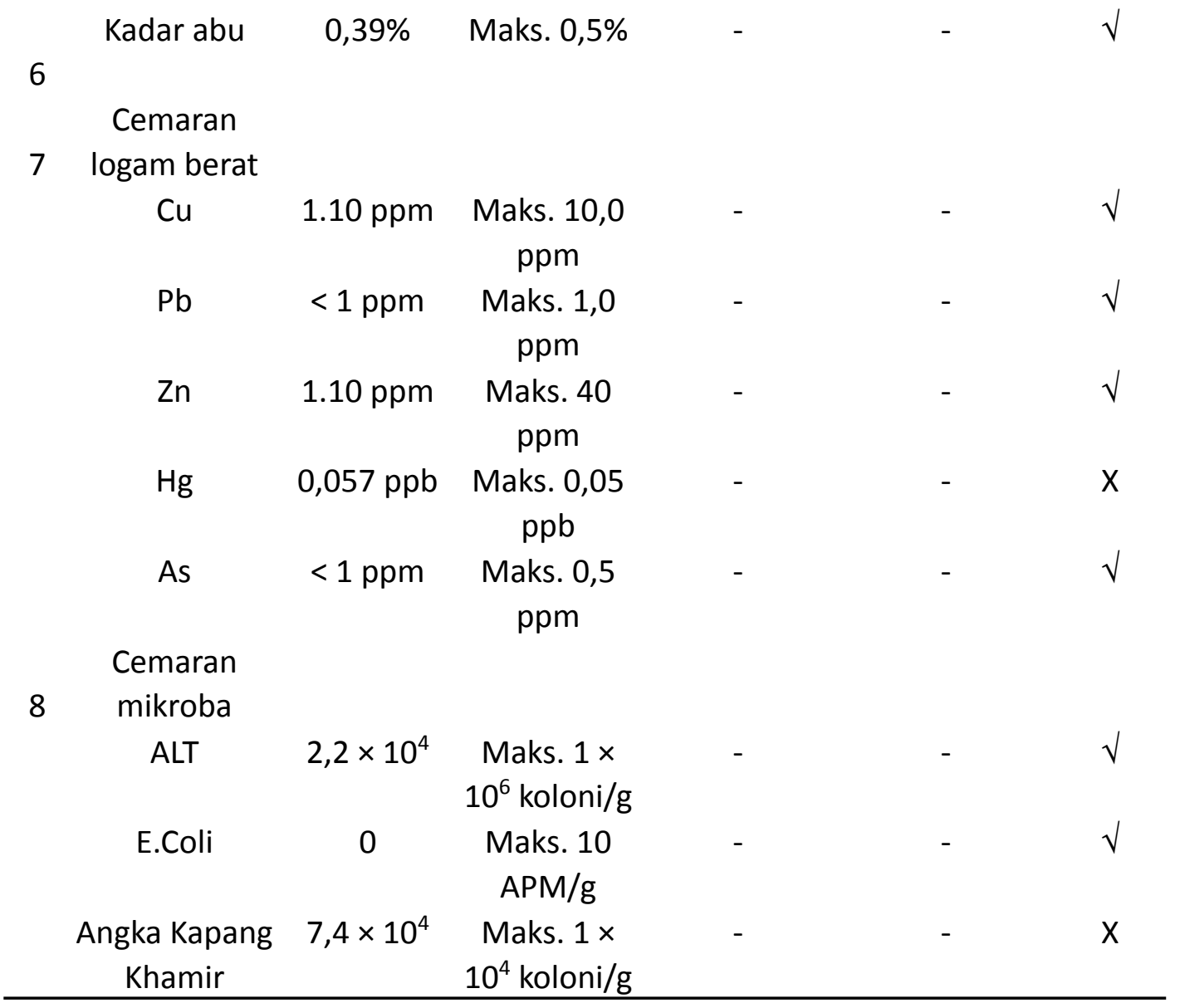

Keterangan Tabel :

$\checkmark$ : Memenuhi standar

$\mathrm{X}$ : Tidak memenuhi standar 